\title{
Identification of a coronary stem cell in the human heart
}

\author{
Annarosa Leri, Toru Hosoda, Jan Kajstura, Piero Anversa, and Marcello Rota \\ Departments of Anesthesia and Medicine, and Division of Cardiovascular Medicine, Brigham and \\ Women's Hospital, Harvard Medical School, 75 Francis Street, Boston, MA 02115, USA
}

\begin{abstract}
Human ischemic cardiomyopathy is characterized by de novo cardiomyogenesis, which is limited to the surviving portion of the ventricle, and by organ hypertrophy that develops as a chronic response to ischemic injury. Although myocyte hypertrophy and myocyte regeneration restore the original myocardial mass, the coronary vasculature remains defective and the extent and regulation of myocardial perfusion are severely impaired. Recently, vascular stem cells (VSCs) have been identified in the coronary circulation. VSCs express c-kit and the vascular endothelial growth factor receptor-2, KDR. These cells are self-renewing, clonogenic, and multipotent in vitro and in vivo. In animal models of critical coronary artery stenosis, VSCs form large conductive coronary arteries and their distal branches. This degree of vasculogenesis replaces partly the function of the occluded coronary artery improving myocardial perfusion and positively interfering with the development of the post-infarction myopathy. Cell therapy directed to the restoration of the integrity of the coronary circulation, the replacement of atherosclerotic coronary vessels, or both, would change dramatically the goal of cell therapy for the ischemic heart: the prevention of myocardial injury would become the endpoint of cell therapy rather than the partial recovery of established damage.
\end{abstract}

\section{Keywords}

Vasculogenesis; Coronary vascular stem cells; Ischemic heart; Cell therapy

\section{Introduction}

Acute and chronic post-infarction heart failure is characterized by de novo cardiomyogenesis which, however, is limited to the surviving portion of the ventricle [1-3]. Small areas of spontaneous myocardial regeneration which invade the infarct shortly after the ischemic event have been identified [3]. Newly formed cardiomyocytes together with myocyte hypertrophy expand the viable myocardium, reconstituting a significant portion of the lost tissue. At times, the growth response exceeds the magnitude of the infarct [4], but organ hypertrophy typically shows a defective coronary vasculature with alterations in the extent and regulation of myocardial perfusion [5]. Abnormalities in the balance between oxygen demand and supply have been viewed as critical determinants of the evolution of the human disease. Pathology of the coronary circulation, in combination with humoral, mechanical, and biochemical factors, sustains the ischemic myopathy and conditions its evolution to terminal failure [6]. Cell therapy directed to the restoration of the integrity and/ or the replacement of atherosclerotic coronary vessels would change dramatically the goal of cell therapy for the ischemic heart: the prevention of myocardial injury would become the endpoint of cell therapy rather than the partial repair of established damage.

(C) Springer-Verlag 2011

Correspondence to: Annarosa Leri. 
The recognition of progenitor cells with vasculogenic potential raises the possibility that the evolution of coronary artery disease (CAD) may be delayed or reversed by restoring the integrity of the vessel wall. The activation of vascular stem cells (VSCs), distributed throughout the coronary circulation, may replace atherosclerotic lesions with stem cellderived smooth muscle cells (SMCs) and endothelial cells (ECs), restoring the integrity of the vessel wall. If reverse remodeling of preclinical atherosclerosis becomes feasible, primary prevention of CAD would be accomplished, markedly attenuating the incidence of acute myocardial infarction and chronic ischemic cardiomyopathy.

\section{Prenatal vasculogenesis}

During embryogenesis, the formation of vessels is critical for the proper arrangement of organ architecture. The first vascular structures appear in the embryo soon after gastrulation and consist of small aggregates of mesodermal progenitors. Cells in these clusters, known as blood islands, undergo partial lineage commitment giving rise to an external layer of endothelial precursors and a central core of hematopoietic precursors [7]. The spatially and temporally close developmental association of endothelial and hematopoietic cells in mammals and avian species strongly suggests that these two lineages share a common precursor [8]. However, the original observation concerning the derivation of blood and vascular cells from a common bipotent progenitor has been challenged and yolk sac blood islands were found to derive from multiple clonal unipotent precursors [9].

In avian species, hemangioblasts are considered critical for the development of the coronary circulation [10]. Hemangioblasts reside in the extracardiac structure named proepicardium which is located near the venous pole of the heart early in development. Myocardiumderived bone morphogenetic protein signals regulate the protrusion and attachment of the proepicardium to the looping heart tube [10]. Hemangioblasts migrate from the proepicardium to the avascular heart tube, giving rise first to the primitive epicardium and subsequently to the endothelial and smooth muscle layers of the coronary blood vessels. Endothelial precursors coalesce to form a primitive vascular plexus which undergoes extensive remodeling and patterning to form a network that resembles the mature coronary artery tree.

In the mouse, the identification of an equivalent hemangioblast with both hematopoietic and vascular potential during gastrulation remains controversial [11]. Support in favor of the existence of the hemangioblast during mouse development has been provided by embryonic stem cell differentiation studies in vitro [8]. The embryo-derived hemangioblasts correspond to a subpopulation of mesoderm that co-expresses brachyury and flk-1. Hemangioblasts are found at highest frequency in the posterior region of the primitive streak, indicating that the initial stages of haematopoietic and vascular commitment occur before blood island development in the yolk sac [8]. However, the recent identification of clusters of hematopoietic stem cells (HSCs) attached to the endothelium of the dorsal aorta has led to the hypothesis that the hemangioblast generates hematopoietic cells through the formation of a hemogenic endothelium intermediate $[12,13]$. The transition from hemogenic endothelium to HSCs has been documented by in vivo imaging in the zebrafish embryo [12]. Moreover, time-lapse confocal imaging of thick slices of mouse embryo has demonstrated the dynamic emergence of phenotypically defined HSCs directly from ventral aortic hemogenic endothelial cells [13]. These data challenge the concept of the hemangioblast as a cell of mesenchymal or mesodermal origin that can give rise to both blood cells and the endothelium.

In spite of this controversy, the vascular endothelial growth factor receptor-2 (VEGFR-2), flk-1/KDR, is considered an essential clue for vessel formation. The flk1 double mutant 
mice are embryonic lethal with no appearance of blood or blood vessels [14]. Importantly, the VEGFR-2 is the earliest marker of angioblast precursors, potentially identifying not only hemangioblasts [15] but also progenitors with broader mesodermal potential [16]. During embryonic development in the mouse, flk-1-positive cells have been isolated and found to possess the ability to acquire in vitro multilineage differentiation including the cardiomyocyte and SMC phenotypes [17]. The endocardium and a population of cells in the myocardium originate from a pool of flk-1-positive cells, suggesting that endothelial and myocardial lineages develop, at least in part, from a common progenitor [18]. Using the embryonic stem cell differentiation model, multipotent flk-1 cardiovascular progenitors have been identified; these cells generate colonies of ECs, SMCs, and myocytes [17].

Collectively, these results suggest that in the embryo, the growth of flk-1 progenitor cells may exceed hematopoiesis and vasculogenesis. However, questions have been raised on the multipotentiality of flk-1 primitive cells [19]. Whether the expression of flk-1 early in the embryo is linked to a multipotent mesodermal progenitor cell, which subsequently specializes in distinct mesodermal lineages, remains to be determined. Similarly, it is unknown whether flk-1 is restricted to multipotent stem cells in the adult organism, although its expression has been linked to the multipotentiality of cell lines derived from adult bone marrow [20] and embryonic dorsal aorta [21].

Dynamic cardiomyogenesis characterizes the response of the damaged heart prenatally and shortly after birth. During gestation, the embryonic fetal heart can react to various types of tissue injuries including toxin exposure, maternal malnutrition, and ischemia by activating a compensatory growth response [22]. In the adult zebrafish, cardiac regeneration takes place after resection of up to $20 \%$ of the ventricle. Traditionally, muscle reconstitution in this model has been considered to be mediated by cardiomyocyte proliferation [23] while vasculogenesis is dictated by the migration of epicardial-derived stem cells to the newly formed myocardium [24]. A spontaneous regenerative response has been observed after surgical resection of the apex of the left ventricle in the neonatal mouse heart [25]. Again, cardiomyocyte proliferation was viewed as the crucial cell process, promoting cardiac repair.

\section{Postnatal vasculogenesis}

In adulthood, functionally competent vascular structures provide blood supply to the entire organism. In contrast to an active vessel growth in the embryo, it is generally assumed that adult coronary vessels are quiescent. However, expansion of the coronary vasculature continues postnatally to accommodate myocardial thickening that results from physiological myocyte proliferation and hypertrophy. In the early stages of postnatal life, the growth of the capillary microvasculature exceeds the growth of the muscle mass [26]. Murine capillary density increases three- to fourfold in the first 3 weeks of life and the number of arterioles approximately tenfold [27]. The insertion of new capillaries among the myocytes increases the ratio of capillary profiles-to-myocyte profiles from a value of $\sim 0.3$ at 11 days after birth to $0.8-0.9$, typical of the adult organ [5]. This process maintains relatively constant, the average intercapillary distance from the second week of postnatal growth to adulthood.

A certain degree of vascular growth is considered possible after tissue injury [27]. This process can be mediated by three separate mechanisms: (a) angiogenesis that corresponds to the sprouting of mature ECs from pre-existing vessels in response to angiogenic growth factors [27]; (b) vasculogenesis that corresponds to the sites of active neovascularization being mediated by the migration of circulating endothelial progenitor cells (EPCs) from the bone marrow [28]; and (c) adaptive arteriogenesis or collateral vessel formation that corresponds to the development of large vessels from pre-existing arteriolar anastomoses 
[27]. The latter is triggered by shear stress which upregulates angiogenic and inflammatory factors. At the site of tissue vascularization, ECs are assumed to originate from the intima of adjacent pre-existing blood vessels while SMCs are recruited from a pool of circulating cells or, in analogy to atherogenesis, from mature SMCs within the media [27]. The identification of EPCs in the bone marrow and in the circulating blood has demanded a reconsideration of traditional vascular biology.

Following the discovery of EPCs in 1997 [28], numerous classes of bone marrow-derived circulating cells have been termed EPCs. Although functional assays have been systematically introduced and the pattern of expression of surface markers characterized, a unifying definition of EPC has not emerged. Substantial differences in the colony-forming protocol have resulted in the generation of unrelated cell populations, including blood island-like clusters of differentiating ECs [28, 29] and hematopoietic cells forced by culture conditions to form ECs [30] but failing to generate vessels in vivo [31]. Importantly, mononuclear cell adhesion to matrix substrate-coated dishes results in enrichment for monocytes, which express EC markers but cannot be equated to EPCs [31]. Based on these findings, the alternative hypothesis has been raised that monocytes-macrophages may regulate the angiogenic response in vivo and, therefore, have been defined circulating angiogenic cells. Finally, the evolution of mononuclear cells in culture has been monitored over time and early outgrowth colonies mostly composed of hematopoietic cells have been distinguished from late outgrowth colonies prevalently formed of ECs [32].

Similarly, the analysis of the surface phenotype of putative EPCs has not provided a definitive answer concerning their identity. Originally, it was assumed that the combination of hematopoietic and endothelial markers was a hallmark of EPCs but the concomitant presence of these epitopes identifies both blood-forming cells and EC-generating cells. Available data have critically been analyzed in a recent review [31] leading to the conclusion that functional EPCs correspond to cells that do not express CD45, CD14, and $\mathrm{CD} 115$, do not ingest bacteria, display high proliferative potential at a clonal level, form tubules in co-culture with lung fibroblasts, or generate de novo vessels in vivo [31]. A standardized series of in vitro and in vivo assays has been proposed to establish the criteria required for the recognition of bona fide EPCs [see ref. 32; Table 1].

Although there is a disagreement concerning the magnitude of the process, migration and homing of putative EPCs to regions of damage have been shown to contribute to EC turnover and vessel growth [28], providing an alternative mechanism of vessel repair [33]. EPCs form an endothelial lining in vascular grafts and on the surface of left ventricular assist devices. EPC number is inversely correlated with cardiovascular mortality [30], suggesting that these cells promote vasculogenesis [33]. However, EPCs cannot prevent or correct atherosclerotic lesions, or generate conductive and resistance coronary arteries.

A fundamental issue in need of resolution is the identification of a niche located in the bone marrow or in the vessel wall that regulates the growth, commitment, and migration of EPCs. In the absence of this information, the origin of these cells and their actual relevance for vessel formation in physiological and pathological conditions may be difficult to establish. Moreover, it remains unclear whether EPCs possess the ability to transdifferentiate into SMCs and form coronary arterioles. The beneficial effect of EPCs and unselected bone marrow cells on the evolution of the post-infarcted heart has been attributed mostly to enhanced capillary density and to a lesser extent to the formation of SMC-covered vessels and cardiomyocytes [34]. The claim has been made that human aortic endothelial cell lines contain a subpopulation of EPCs [35] but the existence of these cells in vivo and their relevance for vessel homeostasis and repair remains to be shown. Cells with hemangioblastlike characteristics have been found in human and mouse adult tissues suggesting that the 
hemangioblast is not a transient cell population which is present exclusively during the development [36]. Similarly, stem cells with hemangioblast or mesoangioblast features have been isolated from the peripheral blood, bone marrow, and adipose tissue [37]. These cell classes differentiate in vitro in endothelial cell and hematopoietic lineages and form new vessels in vivo. Additional experimental evidence suggests that the subendothelial region, the adventitial layer of the vascular wall, and the pericyte fraction harbor several multipotent stem/progenitor cells, including mesenchymal stromal cells, HSCs, and SMC progenitors [37]. However, the existence of vascular stem cells which possesses the fundamental properties of stemness - clonogenicity, self-renewal, and multipotentiality—and reside within structures with the architectural and molecular organization of stem cell niches has not been proven yet. The possibility that progenitor cells reside in the vessel wall and contribute to the homeostasis of coronary vessels and vasculogenesis has only recently been considered [38].

\section{Coronary vascular stem cells}

Based on the characteristics of tissue specific adult stem cells, vasculogenesis may depend on the growth and commitment of stem/progenitor cells distributed in the vessel wall. In an analogy to stem cell-regulated organs, vascular niches are expected to be composed of quiescent VSCs that following the activation leave the niche area and give rise to highly proliferating transit-amplifying cells which differentiate into SMCs, ECs, and adventitial fibroblasts. The localization of VSCs in the wall may correspond to the vasculogenic zones, which include the subendothelial region, the interface between SMCs and the advential layer, and the periadvential area (Fig. 1).

A fundamental question concerns whether the human coronary circulation is regulated by a resident VSC or whether the coronary system is an organ permissive for vascular repair mediated by exogenous cells originated from the bone marrow. The acquisition of this information requires the documentation of vascular niches and the identification of the mechanisms of division of VSCs. Moreover, it has to be established whether VSCs are able to repair discrete areas of intimal and medial damage and/or generate a biological bypass integrated structurally and functionally with existing coronary vessels. The possibility that the homeostasis and growth of the coronary circulation in humans is modulated by VSCs is supported by heart embryology. The distinct embryonic origin of cardiomyocytes and coronary vessels supports the notion that the adult heart may contain two populations of highly immature cells, which are characterized by preferential, although not exclusive, commitment to the myocyte and vascular cell lineages, respectively. Based on the finding that VEGFR-2-positive cells have a powerful vasculogenic potential in prenatal life, the expression of the receptor tyrosine kinase flk-1/KDR has been employed together with c-kit to isolate a population of putative VSCs and identify their niches in the adult mammalian heart.

By this approach, it was possible to document that vascular niches are distributed throughout the coronary circulation [38] while myocardial niches occupy the interstitial space in the myocardium [39, 40]. Vascular niches, composed of clusters of cells expressing c-kit, have been identified in epicardial coronary arteries, arterioles, and capillaries (Fig. 2). In all cases, VSCs express KDR, but are negative for CD45 and tryptase excluding their bone marrow origin and the contribution of mast cells to this cell pool. VSCs are located in the intima, media, and adventitia of different classes of coronary vessels of mice, rats, dogs, and humans [38]. The gap and adherens junction proteins connexin 43 and N-cadherin are expressed at the interface with ECs, SMCs, and fibroblasts, suggesting that these cells may function as supporting cells. 
Cell-to-cell communication is a regulatory mechanism of CSC function [40-42]. Electrical and metabolic coupling via gap junctions plays an important role in the growth behavior of primitive cells. In several organs, gap junctions favor replication, migration, and maturation of progenitor cells. A latent network of gap junctions formed by connexin 43 is present between quiescent HSCs and stromal cells; this system is upregulated during HSC division modulating clonal growth [43-45]. Connexin 43 deficiency impairs hematopoiesis and embryos lacking connexin 43 have a lower number of HSCs [43]. Moreover, the distribution of connexins defines the functional domains of actively dividing neurogenic precursors [46]. A similar mechanism is operative in cardiac niches [40] and in vascular niches [38]. Dye transfer assays are commonly utilized to establish coupling between cells [43]. VSCs have been shown to form functional gap junctions with ECs, SMCs, and fibroblasts. Collectively, these observations point to the presence of an unsuspected VSC located within the wall of coronary vessels distinct from the previously identified CSCs which are distributed within the myocardium.

Human VSCs are negative for hematopoietic markers and various markers of cardiovascular lineages. When plated in single wells, VSCs form multicellular clones composed of cells positive for c-kit and KDR [38]. Clonogenic VSCs exposed to differentiating medium express transcription factors and cytoplasmic and membrane proteins specific to vascular ECs and SMCs, and, to a lesser extent, myocytes. With respect to the previously identified CSCs, VSCs form 4.9-fold more SMCs and 5.7-fold more ECs. Stem cells divide symmetrically and asymmetrically, and these growth patterns are controlled, respectively, by uniform and non-uniform distribution of the cell fate determinants Numb and $\alpha$-adaptin [38, 39]. VSCs have the ability to divide symmetrically giving rise to two daughter stem cells and asymmetrically forming one daughter stem cell and one daughter committed cell that express Ets1 or GATA6. Thus, VSCs are self-renewing, clonogenic, and multipotent in vitro; they are stored in vascular niches and may possess specialized functions devoted to the turnover of ECs and SMCs and vasculogenesis. The lack of bone marrow epitopes on the VSC surface, the presence of sites of storages in the vessel wall, and the ability of VSCs to divide asymmetrically strongly suggest that coronary VSCs reside in the heart. Although it cannot be excluded that primitive cells migrate from the bone marrow and home to the coronary vessel wall, the restoration of the integrity of the coronary vasculature and its regeneration appears to depend mostly on a resident pool of immature cells.

In these studies, an effort was made to identify stem cells with potential therapeutic import in humans, precluding the use of a lineage tracing approach. Fate mapping strategy, which is commonly employed to track the origin of cells and their destiny, would represent the ideal retrospective assay for the study of vascular turnover when the expression of the fluorescent label is placed under the control of the promoter of genes coding for specific proteins. However, this protocol provides information at the level of populations of cells which share the reporter gene but fail to demonstrate in vivo the self-renewal, clonogenicity, and multipotentiality of single progenitor cells. This inherent limitation makes it impossible to establish with certainty the identity of the ancestors of ECs and SMCs [47].

An alternative retrospective protocol is based on the stable integration of proviral integrants in the genome of the infected cells. The insertion site of the viral genome is inherited by the entire population derived from the parental cell [48]. After the viral sequence is integrated, the progeny of the single infected cell is characterized by the inherited genomic region. Clonal tracking of individual mouse and human c-kit-positive CSCs has documented that these cells possess the fundamental properties of stem cells in vivo under physiological conditions and following an injury. By this approach, the existence of a direct link between human CSCs and their committed myocyte progeny has been demonstrated [48]. This strategy remains to be applied to the characterization of VSCs. 


\section{Gene expression profile of coronary VSCs}

Analysis of the transcriptome allows the recognition of genes expressed differentially in stem cell classes and helps to identify divergent patterns and functional background as well as specific signaling pathways that could be activated to promote stem cell growth or differentiation. The self-renewal property of stem cells is regulated by a multitude of genes, including FGF4 and telomerase [49, 50]. Among the self-renewal genes, FGF4, telomerase, Myst1 and Myst2, and Sox1 are represented equally in VSCs and CSCs but whether this molecular characteristic is sufficient to control the kinetics of these stem cell classes, favoring in both cases the generation of daughter stem cells could not be established. However, GDF3 is higher in CSCs than in VSCs. GDF3 is part of a group of genes that flank Nanog, forming a chromatin loop of regulatory elements. The integrity of this region of the genome is maintained by Oct 4 and is essential for the preservation of self-renewal in embryonic stem cells [51].

Sox2, c-Myc, Klf4, and Oct4 reprogram the growth and differentiation behavior of adult somatic cells and govern the proliferation and pluripotency of embryonic stem cells [51]. Their expression is comparable in VSCs and CSCs, suggesting that these two stem cell classes possess similar levels of plasticity and that stemness and multipotentiality may be regulated by the same group of genes. Genes that modulate asymmetric division Numb, Pard6A, and Prox 1 are uniformly present, ensuring the ability of VSCs and CSCs to selfrenew, and create adequate progeny. Multiple cell cycle regulators, including cyclins D1, D2, A2, and cdc2 and cdc42 show comparable levels of transcripts in VSCs and CSCs.

These data at the molecular level are consistent with the functional assays performed in vitro and in vivo. The long-term proliferative potential of VSCs and CSCs, together with their ability to undergo asymmetric division, indicates that both cell categories possess high intrinsic self-renewal ability.

However, vascular-restricted genes and myocyte-specific genes appear to be poised for expression in VSCs and CSCs, respectively. The mRNA quantities of the EC transcription factor Vezf1, vascular adhesion protein VCAM1, and the EC markers eNOS [52], vWf, and multimerin [53] are higher in VSCs than those in CSCs. Similarly, transcripts for GATA6 and contractile proteins $\alpha$-SMA, SM22a, and smoothelin [54, 55] are more expressed in VSCs than in CSCs. Conversely, CSCs show increased transcripts for Nkx2.5, $\beta$-myosin heavy chain, and myosin heavy chain 7b [56]. Thus, VSCs and CSCs manifest a preferential lineage potential; specific cell phenotypes became apparent when commitment was induced.

Among the transcripts of the Notch pathway, the Delta-like 3 ligand and the downstream regulator DTX1 are more abundant in CSCs than VSCs, respectively. Importantly, the Notch1 receptor is a critical determinant of the transition of CSCs to amplifying myocytes [57]. Two genes relevant to vascular cell turnover and repair, PPAR- $\gamma$ and Klf5, are upregulated in the VSCs. PPAR- $\gamma$ is present in ECs and SMCs and is implicated in vessel homeostasis [58], whereas Klf5 is expressed abundantly in vascular structures during development and in response to injury [59]. These findings at the transcriptional level, together with the data at the protein level at baseline and after differentiation are consistent with the notion that VSCs and CSCs are separate classes of progenitor cells with distinct biological properties and specific independent functions (Fig. 3).

\section{Vessel regeneration}

Resident c-kit-positive CSCs have been shown to possess a great regenerative ability in experimental models of the human disease [3, 39, 60-62]. However, the vasculogenic potential of CSCs is restricted to the formation of capillary vessels and small resistance arterioles. During tissue repair, CSCs acquire predominantly the cardiomyogenic fate while 
vessel growth is modest and strikingly inferior to myocyte formation. Successful interventions for the treatment of CAD require the generation of large conductive arteries which may be achieved by a pool of stem cells with specific vasculogenic properties. Critical stenosis of the left anterior descending coronary artery (LAD) in dogs mimics the development of ischemic cardiomyopathy in humans representing the ideal animal model for the assessment of the vasculogenic properties of VSCs. Importantly, a significant increase in coronary blood flow (CBF) at rest or after stressful conditions does not occur in dogs with critical stenosis, in which the generation of collaterals never results in the restoration of CBF in the presence of an occluded major coronary artery [63].

Thirty days after the delivery of human VSCs in proximity of the stenotic vessel, a slow return of CBF was observed after release of the transiently occluded LAD, suggesting the formation of coronary vessels in the presence of critical stenosis. These changes in CBF were not dictated by perfusion of the occluded LAD but by the vessels generated around the affected artery. Histologically, large and intermediate newly formed coronary arteries together with resistance arterioles and capillary structures were identified. Vasculogenesis involved all components of the coronary circulation from vessels $<100 \mu \mathrm{m}$ to $1.5 \mathrm{~mm}$ in diameter, pointing to vessel regeneration as the mechanism of enhanced $\mathrm{CBF}$ and tissue oxygenation in the potentially ischemic myocardium. Importantly, VSCs did not integrate in pre-existing nonfunctional collateral vessels, contributing to their maturation in working vascular structures. The newly formed conductive arteries were made exclusively of human SMCs and ECs, which were the progeny of the injected cells. These functional and morphological observations strongly suggest that the regenerated large conductive coronary arteries were connected with the LAD above the site of constriction, as previously demonstrated in the rat model of coronary occlusion [64], creating a biological bypass. The improvement in CBF was coupled with increased segment length function in the ischemic myocardium where a thin layer of human cardiomyocytes was detected in the epicardial surface.

The functional integration of regenerated vessels has been documented in a small animal model of myocardial infarction by two-photon microscopy. In a manner similar to KDRpositive VSCs, CSCs activated in vitro with IGF-1 and HGF prior to their delivery to the infarcted rat myocardium [64] regenerate conductive, intermediate-sized, and small coronary arteries and arterioles together with capillary structures in vivo. To determine whether new coronary vessels are connected with the aorta and the existing coronary circulation, an ex vivo preparation has been used in which the heart is perfused through the aorta with rhodamine-labeled dextran. This molecule does not cross the endothelium, and it allows the visualization of the coronary vasculature by two-photon microscopy [62]. Newly formed and pre-existing vascular structures can be distinguished based on the presence and absence of the green fluorescence of EGFP. By this approach, large coronary arteries and their branches have been identified within the epimyocardium, border zone, and scarred myocardium of the infarcted rat heart. A direct connection has been recognized between preexisting and generated coronary vessels documenting the integration of temporally distinct, old and new, segments of the coronary vasculature. Thus, VSCs and CSCs may be employed for the reconstitution of damaged myocardium and defective coronary vessels (Fig. 4).

\section{Signaling pathways regulating coronary vessel formation}

A relevant question concerns whether changes in the cardiac microenvironment created by coronary occlusion influence the differentiation of resident progenitor cells into vascular SMCs and ECs, leading to the formation of coronary vessels. Potential candidates include the hypoxia-inducible factor $1 \alpha$ (HIF-1 $\alpha$ ), which is a transcriptional regulator of the stromalderived factor 1 (SDF-1) chemokine [65]. HIF-1 $\alpha$ and SDF-1 are upregulated with ischemia 
and correlate with the oxygen gradient within the tissue [65, 66]. Following coronary artery occlusion, the expression of HIF-1 $\alpha$ and SDF-1 significantly increases at the border of the infarct and within the infarct [64]. HIF-1 $\alpha$ is present in myocyte, EC, and SMC nuclei, whereas SDF-1 is restricted to ECs and SMCs within the wall of coronary vessels. Importantly, IGF-1 and HGF enhance the expression of HIF- $1 \alpha$ transcript and protein, and the formation of SDF-1 in CSCs. These effects are mediated by the activation of the PI3K/ Akt pathway. The inhibition of Akt signaling attenuates the expression of HIF- $1 \alpha$ and the synthesis of SDF-1. These findings point to the critical role that IGF-1-HGF and the PI3K/ Akt pathway may have in the survival and engraftment of CSCs on one hand and HIF-1 $\alpha$ and SDF-1 expression on the other hand [67, 68]. The formation of SDF-1 by ECs and the interaction of ECs with CSCs promote the commitment of CSCs into vascular cells. CSCs express CXCR4, the receptor of SDF-1. This response is potentiated under hypoxic conditions and attenuated when the expression of HIF-1 $\alpha$ is inhibited in ECs. Thus, CSC activation by hypoxia and/or SDF-1 favors the generation of ECs and SMCs.

\section{Conclusions}

The pharmacological and surgical management of patients affected by CAD has improved significantly in the last three decades [69], but, despite these advances, morbidity and mortality for ischemic cardiomyopathy continue to increase and parallel the extension in median lifespan of the population [70]. Bypass surgery and catheter-based reinstitution of CBF have been introduced successfully, but these interventions correct only in part the vascular defects and are limited by the number of surgical grafts, the possibility of restenosis, and the complexity of reintervention in high-risk patients [71]. Moreover, cardiac transplantation for end-stage ischemic cardiomyopathy has age restriction and is limited by the small number of donor hearts. These variables underscore the need for the development of new strategies for the management of coronary atherosclerosis in humans.

Prevention of the development of CAD involves the restoration of the integrity of the vessel wall through the activation of resident vascular progenitor cells which differentiate into ECs and SMCs. Resident human VSCs form large conductive coronary arteries and their distal branches, correcting, at least in part, alterations in blood flow created by prolonged coronary constriction in chronically instrumented conscious dogs. This degree of vasculogenesis replaces partly the function of the occluded coronary artery and its distal branches and improves myocardial perfusion, positively interfering with the development of the postinfarction myopathy. Blood flow to the myocardium can be enhanced only by the formation of arteries and arterioles, whereas capillaries control oxygen diffusion but have no influence on flow regulation [72].

The documentation that undifferentiated cells with angiogenic properties reside in the heart challenges the notion that the bone marrow is the exclusive reservoir or source of stem cells for therapeutic angiogenesis. Moreover, there is no evidence that EPCs or bone marrow cell subsets can form large conductive arteries pointing to KDR-positive VSCs or activated CSCs as the cell of choice for biological coronary bypass. Cell therapy with the generation of coronary vessels by human bone marrow cells has been obtained previously, but this has been restricted to capillary profiles and occasionally small resistance arterioles, which enhance tissue oxygenation but have little impact on flow regulation. From a clinical perspective, the regeneration of large conductive arteries may require the local administration of VSCs, whereas intracoronary and intramyocardial injection of CSCs may be equally effective in promoting myocyte regeneration. Preclinical CAD may be cured by the activation or administration of VSCs that may reverse atherosclerotic lesions. If remodeling of preclinical atherosclerosis can be achieved, true primary prevention of CAD 
would be accomplished and acute coronary syndrome with sudden cardiac death, myocardial infarction, and ischemic cardiomyopathy would be dramatically reduced.

\section{References}

1. Kajstura J, Leri A, Finato N, Di Loreto C, Beltrami CA, Anversa P. Myocyte proliferation in endstage cardiac failure in humans. Proc Natl Acad Sci USA. 1998; 95:8801-8805. [PubMed: 9671759]

2. Beltrami AP, Urbanek K, Kajstura J, Yan SM, Finato N, Bussani R, Nadal-Ginard B, Silvestri F, Leri A, Beltrami CA, et al. Evidence that human cardiac myocytes divide after myocardial infarction. N Eng J Med. 2001; 344:1750-1757.

3. Urbanek K, Torella D, Sheikh F, De Angelis A, Nurzynska D, Silvestri F, Beltrami CA, Bussani R, Beltrami AP, Quaini F, et al. Myocardial regeneration by activation of multipotent cardiac stem cells in ischemic heart failure. Proc Natl Acad Sci USA. 2005; 102:8692-8697. [PubMed: 15932947]

4. Beltrami CA, Finato N, Rocco M, Feruglio GA, Puricelli C, Cigola E, Quaini F, Sonnenblick EH, Olivetti G, Anversa P. Structural basis of end-stage failure in ischemic cardiomyopathy in humans. Circulation. 1994; 89:151-163. [PubMed: 8281642]

5. Anversa, P.; Olivetti, G. Handbook of physiology, the cardiovascular system, the heart. Vol. sect 2 chapter 2. Bethesda, MD: 2002. Cellular basis of physiological and pathological myocardial growth; p. $75-144$.

6. Jessup M, Brozena S. Heart failure. N Engl J Med. 2003; 348:2007-2018. [PubMed: 12748317]

7. Risau W, Flamme I. Vasculogenesis. Annu Rev Cell Dev Biol. 1995; 11:73-91. [PubMed: 8689573]

8. Huber TL, Kouskoff V, Fehling HJ, Palis J, Keller G. Haemangioblast commitment is initiated in the primitive streak of the mouse embryo. Nature. 2004; 432:625-630. [PubMed: 15577911]

9. Ueno H, Weissman IL. Clonal analysis of mouse development reveals a polyclonal origin for yolk sac blood islands. Dev Cell. 2006; 11:519-533. [PubMed: 17011491]

10. Ishii Y, Garriock RJ, Navetta AM, Coughlin LE, Mikawa T. BMP signals promote proepicardial protrusion necessary for recruitment of coronary vessel and epicardial progenitors to the heart. Dev Cell. 2010; 19:307-316. [PubMed: 20708592]

11. Kinder SJ, Tsang TE, Quinlan GA, Hadjantonakis AK, Nagy A, Tam PP. The orderly allocation of mesodermal cells to the extraembryonic structures and the anteroposterior axis during gastrulation of the mouse embryo. Development. 1999; 126:4691-4701. [PubMed: 10518487]

12. Bertrand JY, Chi NC, Santoso B, Teng S, Stainier DY, Traver D. Haematopoietic stem cells derive directly from aortic endothelium during development. Nature. 2010; 464:108-111. [PubMed: 20154733]

13. Boisset JC, van Cappellen W, Andrieu-Soler C, Galjart N, Dzierzak E, Robin C. In vivo imaging of haematopoietic cells emerging from the mouse aortic endothelium. Nature. 2010; 464:116-120. [PubMed: 20154729]

14. Shalaby F, Ho J, Stanford WL, Fischer KD, Schuh AC, Schwartz L, Bernstein A, Rossant J. A requirement for Flk1 in primitive and definitive hematopoiesis and vasculogenesis. Cell. 1997; 89:981-990. [PubMed: 9200616]

15. Ema M, Faloon P, Zhang WJ, Hirashima M, Reid T, Stanford WL, Orkin S, Choi K, Rossant J. Combinatorial effects of Flk1 and Tal1 on vascular and hematopoietic development in the mouse. Genes Dev. 2003; 17:380-393. [PubMed: 12569129]

16. Ema M, Yokomizo T, Wakamatsu A, Terunuma T, Yamamoto M, Takahashi S. Primitive erythropoiesis from mesodermal precursors expressing VE-cadherin, PECAM-1, Tie2, endoglin, and CD34 in the mouse embryo. Blood. 2006; 108:4018-4024. [PubMed: 16926294]

17. Coultas L, Chawengsaksophak K, Rossant J. Endothelial cells and VEGF in vascular development. Nature. 2005; 438:937-945. [PubMed: 16355211]

18. Yang L, Soonpaa MH, Adler ED, Roepke TK, Kattman SJ, Kennedy M, Henckaerts E, Bonham K, Abbott GW, Linden RM, et al. Human cardiovascular progenitor cells develop from a KDR ${ }^{+}$ embryonic-stem-cell-derived population. Nature. 2008; 453:524-528. [PubMed: 18432194] 
19. Kinder SJ, Loebel DA, Tam PP. Allocation and early differentiation of cardiovascular progenitors in the mouse embryo. Trends Cardiovasc Med. 2001; 11:177-184. [PubMed: 11597828]

20. Jiang Y, Bn J, Reinhardt RL, Schwartz RE, Keene CD, Ortiz-Gonzalez XR, Reyes M, Lenvik T, Lund T, Blackstad M, et al. Pluripotency of mesenchymal stem cells derived from adult marrow. Nature. 2002; 418:41-49. [PubMed: 12077603]

21. Hirai H, Ogawa M, Suzuki N, Yamamoto M, Breier G, Mazda O, Imanishi J, Nishikawa S. Hemogenic and nonhemogenic endothelium can be distinguished by the activity of fetal liver kinase (Flk)-1 promoter/enhancer during mouse embryogenesis. Blood. 2003; 101:886-893. [PubMed: 12393724]

22. Drenckhahn D, Schwarz QP, Gray S, Laskowski A, Kiriazis H, Ming Z, Harvey RP, Du XJ, Thorburn DR, Cox TC. Compensatory growth of healthy cardiac cells in the presence of diseased cells restores tissue homeostasis during heart development. Dev Cell. 2008; 15:521-533. [PubMed: 18854137]

23. Poss KD, Wilson LG, Keating MT. Heart regeneration in zebrafish. Science. 2002; 298:21882190. [PubMed: 12481136]

24. Lepilina A, Coon AN, Kikuchi K, Holdway JE, Roberts RW, Burns CG, Poss KD. A dynamic epicardial injury response supports progenitor cell activity during zebrafish heart regeneration. Cell. 2006; 127:607-619. [PubMed: 17081981]

25. Porrello ER, Mahmoud AI, Simpson E, Hill JA, Richardson JA, Olson EN, Sadek HA. Transient regenerative potential of the neonatal mouse heart. Science. 2011; 331:1078-1080. [PubMed: 21350179]

26. Olivetti G, Anversa P, Loud AV. Morphometric study of early postnatal development in the left and right ventricular myocardium of the rat. II. Tissue composition, capillary growth, and sarcoplasmic alterations. Circ Res. 1980; 46:503-512. [PubMed: 6444555]

27. Carmeliet P, Jain RK. Angiogenesis in health and disease. Nat Med. 2003; 9:653-660. [PubMed: 12778163]

28. Asahara T, Murohara T, Sullivan A, Silver M, van der Zee R, Li T, Witzenbichler B, Schatteman G, Isner JM. Isolation of putative progenitor endothelial cells for angiogenesis. Science. 1997; 275:964-967. [PubMed: 9020076]

29. Ito H, Rovira II, Bloom ML, Takeda K, Ferrans VJ, Quyyumi AA, Finkel T. Endothelial progenitor cells as putative targets for angiostatin. Cancer Res. 1999; 59:5875-5877. [PubMed: 10606226]

30. Hill JM, Zalos G, Halcox JP, Schenke WH, Waclawiw MA, Quyyumi AA, Finkel T. Circulating endothelial progenitor cells, vascular function, and cardiovascular risk. N Engl J Med. 2003; 348:593-600. [PubMed: 12584367]

31. Hirschi KK, Ingram DA, Yoder MC. Assessing identity, phenotype, and fate of endothelial progenitor cells. Arterioscler Thromb Vasc Biol. 2008; 28:1584-1595. [PubMed: 18669889]

32. Kim H, Kim SW, Nam D, Kim S, Yoon YS. Cell therapy with bone marrow cells for myocardial regeneration. Antioxid Redox Signal. 2009; 11:1897-1911. [PubMed: 19203213]

33. Losordo DW, Dimmeler S. Therapeutic angiogenesis and vasculogenesis for ischemic disease: part II: cell-based therapies. Circulation. 2004; 109:2692-2697. [PubMed: 15184293]

34. Yoon CH, Koyanagi M, Iekushi K, Seeger F, Urbich C, Zeiher AM, Dimmeler S. Mechanism of improved cardiac function after bone marrow mononuclear cell therapy: role of cardiovascular lineage commitment. Circulation. 2010; 121:2001-2011. [PubMed: 20421519]

35. Ingram DA, Mead LE, Moore DB, Woodard W, Fenoglio A, Yoder MC. Vessel wall-derived endothelial cells rapidly proliferate because they contain a complete hierarchy of endothelial progenitor cells. Blood. 2005; 105:2783-2786. [PubMed: 15585655]

36. Xiong JW. Molecular and developmental biology of the hemangioblast. Dev Dyn. 2008; 237:1218-1231. [PubMed: 18429046]

37. Pacilli A, Pasquinelli G. Vascular wall resident progenitor cells: a review. Exp Cell Res. 2009; 315:901-914. [PubMed: 19167379]

38. Bearzi C, Leri A, Lo Monaco F, Rota M, Gonzalez A, Hosoda T, Pepe M, Qanud K, Ojaimi C, Bardelli S, et al. Identification of a coronary vascular progenitor cell in the human heart. Proc Natl Acad Sci USA. 2009; 106:15885-15890. [PubMed: 19717420] 
39. Bearzi C, Rota M, Hosoda T, Tillmanns J, Nascimbene A, De Angelis A, Yasuzawa-Amano S, Trofimova I, Siggins RW, Lecapitaine N, et al. Human cardiac stem cells. Proc Natl Acad Sci USA. 2007; 104:14068-14073. [PubMed: 17709737]

40. Urbanek K, Cesselli D, Rota M, Nascimbene A, De Angelis A, Hosoda T, Bearzi C, Boni A, Bolli R, Kajstura J, et al. Stem cell niches in the adult mouse heart. Proc Natl Acad Sci USA. 2006; 103:9226-9231. [PubMed: 16754876]

41. Tumbar T, Guasch G, Greco V, Blanpain C, Lowry WE, Rendl M, Fuchs E. Defining the epithelial stem cell niche in skin. Science. 2004; 303:359-363. [PubMed: 14671312]

42. Hosoda T, Zheng H, Cabralda-Silva M, Sanada F, Ide-Iwata N, Ogórek B, Ferreira-Martins J, Arranto C, D'Amario D, Del Monte F, et al. Human cardiac stem cell differentiation is regulated by a mircrine mechanism. Circulation. 2011; 123:1287-1296. [PubMed: 21403094]

43. Cancelas JA, Koevoet WL, de Koning AE, Mayen AE, Rombouts EJ, Ploemacher RE. Connexin-43 gap junctions are involved in multiconnexin-expressing stromal support of hemopoietic progenitors and stem cells. Blood. 1996; 498:505.

44. Montecino-Rodriguez E, Leathers H, Dorshkind K. Expression of connexin 43 (Cx43) is critical for normal hematopoiesis. Blood. 2000; 96:917-924. [PubMed: 10910905]

45. Blazsek I, Chagraoui J, Peault B. Ontogenic emergence of the hematon, a morphogenetic stromal unit that supports multipotential hematopoietic progenitors in mouse bone marrow. Blood. 2000; 96:3763-3771. [PubMed: 11090058]

46. Russo RE, Reali C, Radmilovich M, Fernández A, Trujillo-Cenóz O. Connexin 43 delimits functional domains of neurogenic precursors in the spinal cord. J Neurosci. 2008; 28:3298-3309. [PubMed: 18367597]

47. Leri A. Human cardiac stem cells: the heart of a truth. Circulation. 2009; 120:2515-2518. [PubMed: 19996014]

48. Hosoda T, D’Amario D, Cabral-Da-Silva MC, Zheng H, Padin-Iruegas ME, Ogorek B, FerreiraMartins J, Yasuzawa-Amano S, Amano K, Ide-Iwata N, et al. Clonality of mouse and human cardiomyogenesis in vivo. Proc Natl Acad Sci USA. 2009; 106:17169-17174. [PubMed: 19805158]

49. Morrison SJ, Prowse KR, Ho P, Weissman IL. Telomerase activity in hematopoietic cells is associated with self-renewal potential. Immunity. 1996; 5:207-216. [PubMed: 8808676]

50. Mayshar Y, Rom E, Chumakov I, Kronman A, Yayon A, Benvenisty N. Fibroblast growth factor 4 and its novel splice isoform have opposing effects on the maintenance of human embryonic stem cell self-renewal. Stem Cells. 2008; 26:767-774. [PubMed: 18192227]

51. Levasseur DN, Wang J, Dorschner MO, Stamatoyannopoulos JA, Orkin SH. Oct4 dependence of chromatin structure within the extended Nanog locus in ES cells. Genes Dev. 2008; 22:575-580. [PubMed: 18283123]

52. Albrecht EW, Stegeman CA, Heeringa P, Henning RH, van Goor H. Protective role of endothelial nitric oxide synthase. J Pathol. 2003; 199:8-17. [PubMed: 12474221]

53. Hayward CP, Cramer EM, Song Z, Zheng S, Fung R, Massé JM, Stead RH, Podor TJ. Studies of multimerin in human endothelial cells. Blood. 1998; 91:1304-1317. [PubMed: 9454761]

54. Yoshida T, Owens GK. Molecular determinants of vascular smooth muscle cell diversity. Circ Res. 2005; 96:280-291. [PubMed: 15718508]

55. van Eys GJ, Niessen PM, Rensen SS. Smoothelin in vascular smooth muscle cells. Trends Cardiovasc Med. 2007; 17:26-30. [PubMed: 17210475]

56. Olson EN. Gene regulatory networks in the evolution and development of the heart. Science. 2006; 313:1922-1927. [PubMed: 17008524]

57. Boni A, Urbanek K, Nascimbene A, Hosoda T, Zheng H, Delucchi F, Amano K, Gonzalez A, Vitale S, Ojaimi C, et al. Notch1 regulates the fate of cardiac progenitor cells. Proc Natl Acad Sci USA. 2008; 105:15529-15534. [PubMed: 18832173]

58. Duan SZ, Usher MG, Mortensen RM. PPARs: the vasculature, inflammation and hypertension. Curr Opin Nephrol Hypertens. 2009; 18:128-133. [PubMed: 19434050]

59. Suzuki T, Aizawa K, Matsumura T, Nagai R. Vascular implications of the Krüppel-like family of transcription factors. Arterioscler Thromb Vasc Biol. 2005; 25:1135-1141. [PubMed: 15817882] 
60. Beltrami AP, Barlucchi L, Torella D, Baker M, Limana F, Chimenti S, Kasahara H, Rota M, Musso E, Urbanek K, et al. Adult cardiac stem cells are multipotent and support myocardial regeneration. Cell. 2003; 114:1-20. [PubMed: 12859888]

61. Linke A, Muller P, Nurzynska D, Casarsa C, Torella D, Nascimbene A, Castaldo C, Cascapera S, Bohm M, Quaini F, et al. Stem cells in the dog heart are self-renewing, clonogenic, and multipotent and regenerate infracted myocardium, improving cardiac function. Proc Natl Acad Sci USA. 2005; 102:8966-8971. [PubMed: 15951423]

62. Urbanek K, Rota M, Cascapera S, Bearzi C, Nascimbene A, De Angelis A, Hosoda T, Chimenti S, Baker M, Limana F, et al. Cardiac stem cells possess growth factor-receptor systems that after activation regenerate the infracted myocardium improving ventricular function and long-term survival. Circ Res. 2005; 97:663-673. [PubMed: 16141414]

63. Schaper W. Collateral circulation: past and present. Basic Res Cardiol. 2009; 104:5-21. [PubMed: 19101749]

64. Tillmanns J, Rota M, Hosoda T, Misao Y, Esposito G, Gonzalez A, Vitale S, Parolin C, YasuzawaAmano S, Muraski J, et al. Formation of large coronary arteries by cardiac progenitor cells. Proc Natl Acad Sci USA. 2008; 105:1668-1673. [PubMed: 18216245]

65. Ceradini DJ, Kulkarni AR, Callaghan MJ, Tepper OM, Bastidas N, Kleinman ME, Capla JM, Galiano RD, Levine JP, Gurtner GC. Progenitor cell trafficking is regulated by hypoxic gradients through HIF-1 induction of SDF-1. Nat Med. 2004; 10:858-864. [PubMed: 15235597]

66. Abbott JD, Huang Y, Liu D, Hickey R, Krause DS, Giordano FJ. Stromal cell-derived factor-1alpha plays a critical role in stem cell recruitment to the heart after myocardial infarction but is not sufficient to induce homing in the absence of injury. Circulation. 2004; 110:3300-3305. [PubMed: 15533866]

67. Fukuda R, Hirota K, Fan F, Jung YD, Ellis LM, Semenza GL. Insulin-like growth factor 1 induces hypoxia-inducible factor 1-mediated vascular endothelial growth factor expression, which is dependent on MAP kinase and phosphatidylinositol 3-kinase signaling in colon cancer cells. J Biol Chem. 2002; 277:38205-38211. [PubMed: 12149254]

68. Tacchini L, De Ponti C, Matteucci E, Follis R, Desiderio MA. Hepatocyte growth factor-activated NF-kappaB regulates HIF-1 activity and ODC expression, implicated in survival, differently in different carcinoma cell lines. Carcinogenesis. 2004; 25:2089-2100. [PubMed: 15240510]

69. McMurray JJ, Pfeffer MA. Heart failure. Lancet. 2005; 365:1877-1889. [PubMed: 15924986]

70. Sanderson WC, Scherbov S. Average remaining lifetimes can increase as human populations age. Nature. 2005; 435:811-813. [PubMed: 15944703]

71. Blackstone EH, Lytle BW. Competing risks after coronary bypass surgery: the influence of death on reintervention. J Thorac Cardiovasc Surg. 2000; 119:1221-1230. [PubMed: 10838542]

72. Hintze TH, Vatner SF. Reactive dilation of large coronary arteries in conscious dogs. Circ Res. 1984; 54:50-57. [PubMed: 6692499] 


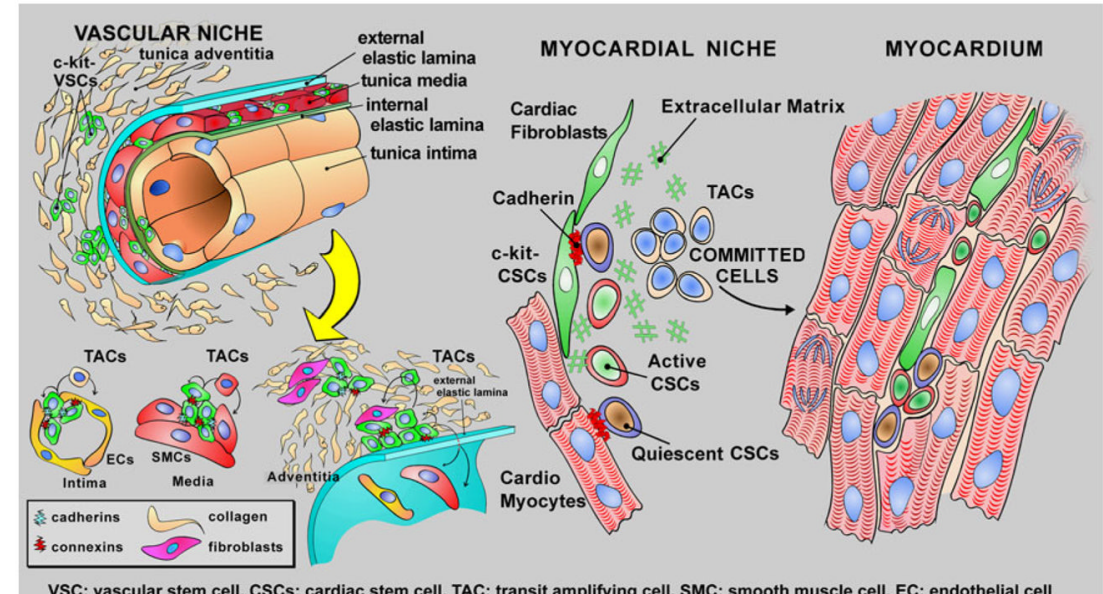

Fig. 1.

Vascular and cardiac stem cells. The distribution and properties of VSCs and CSCs are shown schematically 

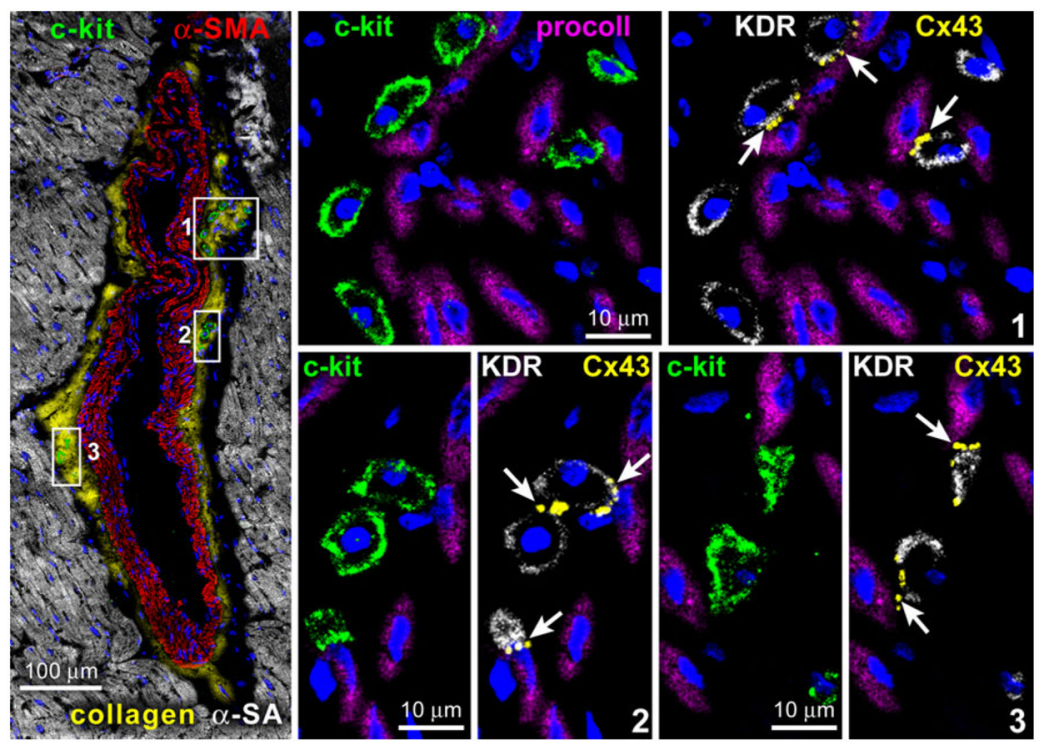

Fig. 2.

Vascular niches. Tangential section of a human epicardial coronary artery composed of a few layers of SMCs ( $\alpha$-SMA; red). At the interface between the adventitia and the SMC layer, three small clusters of c-kit-positive cells (green) are present and are shown at higher magnification in the adjacent panels. The c-kit-positive cells express KDR. Cx43 (arrows) is detected between c-kit-KDR-positive cells and fibroblasts (procoll; magenta).

(Taken from ref. 39 with permission) 

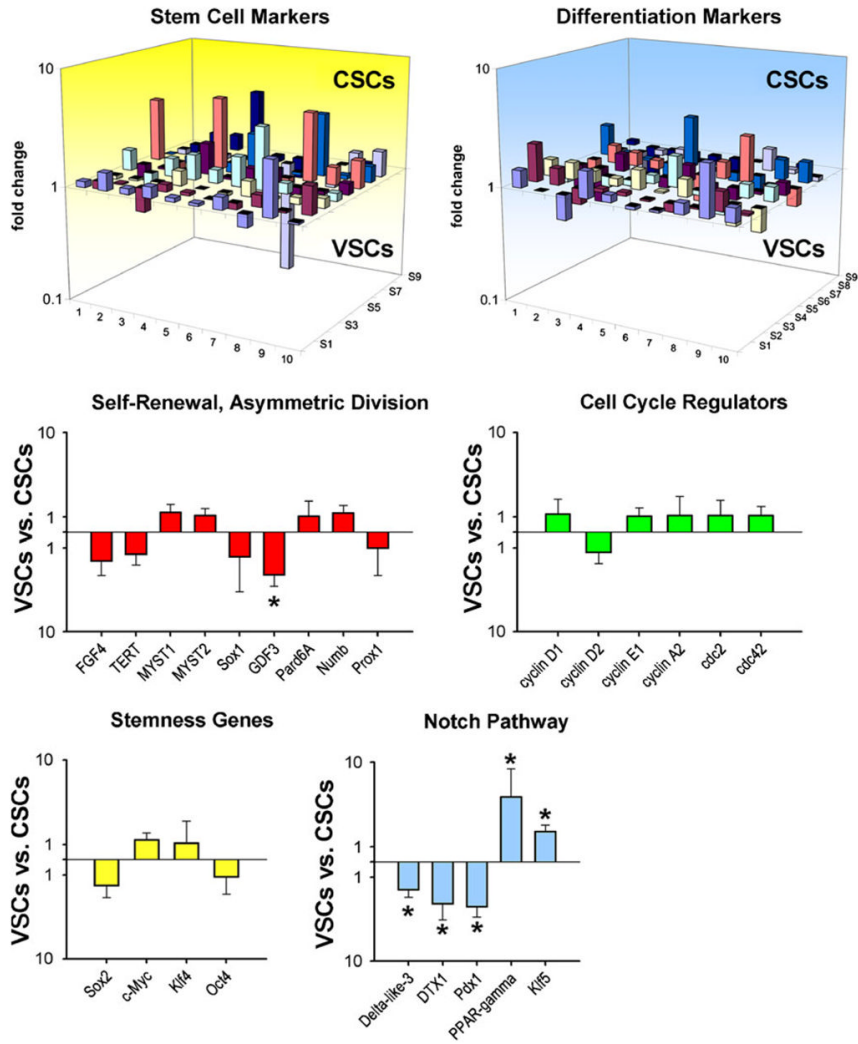

Fig. 3.

Gene expression profile of VSCs and CSCs. Three-dimensional representation of the transcriptional profile of vascular stem cells (VSCs) and cardiac stem cells (CSCs). Bar graphs illustrate the expression of genes discussed in the text. $P<0.05$ between VSCs and CSCs. (Taken from ref. 39 with permission) 

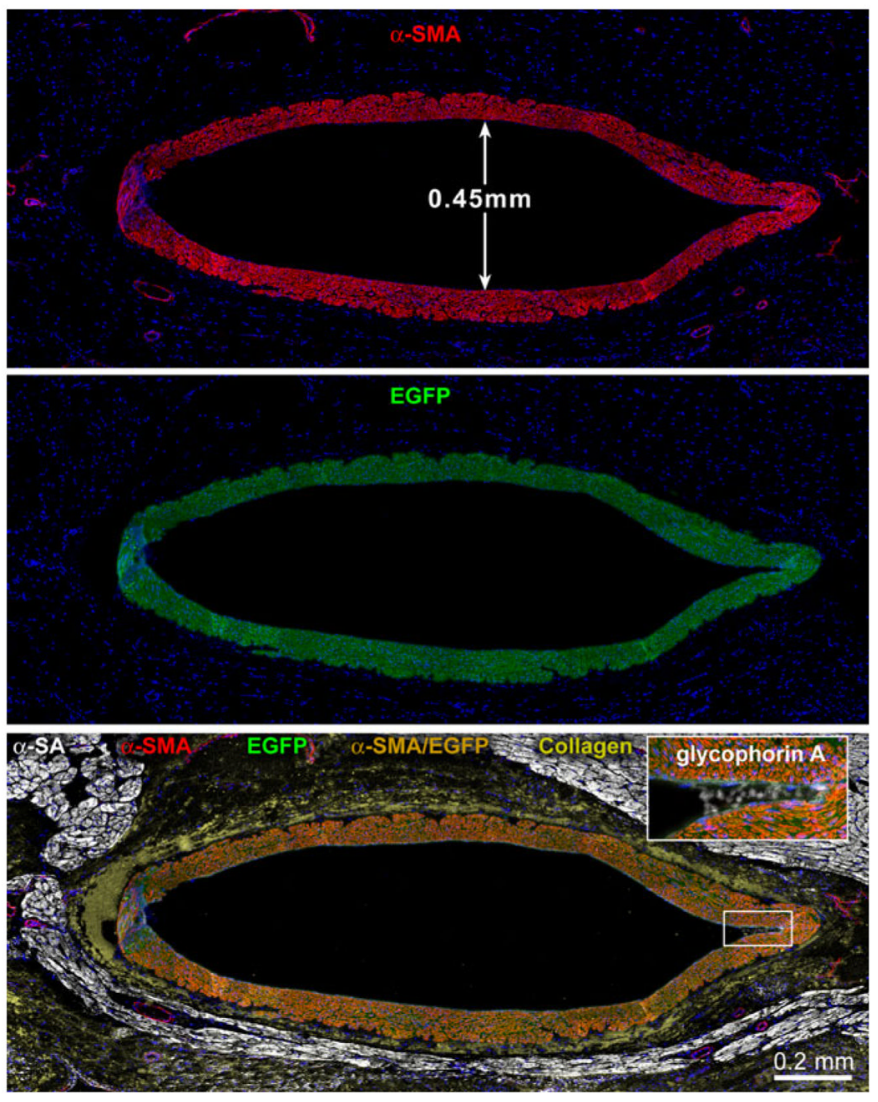

Fig. 4.

Intermediate- and small-sized vessels. Newly formed coronary artery from a heart in which CBF was measured. The vessel wall is positive for $\alpha$-SMA (red), EGFP (green), and $\alpha$-SMA and EGFP (yellowish). Inset: a few red blood cells are present (glycophorin A, white). Myocytes are labeled by $\alpha$-SA (white) and the adventitia by collagen type I and III (yellow). (Taken from ref. 39 with permission) 


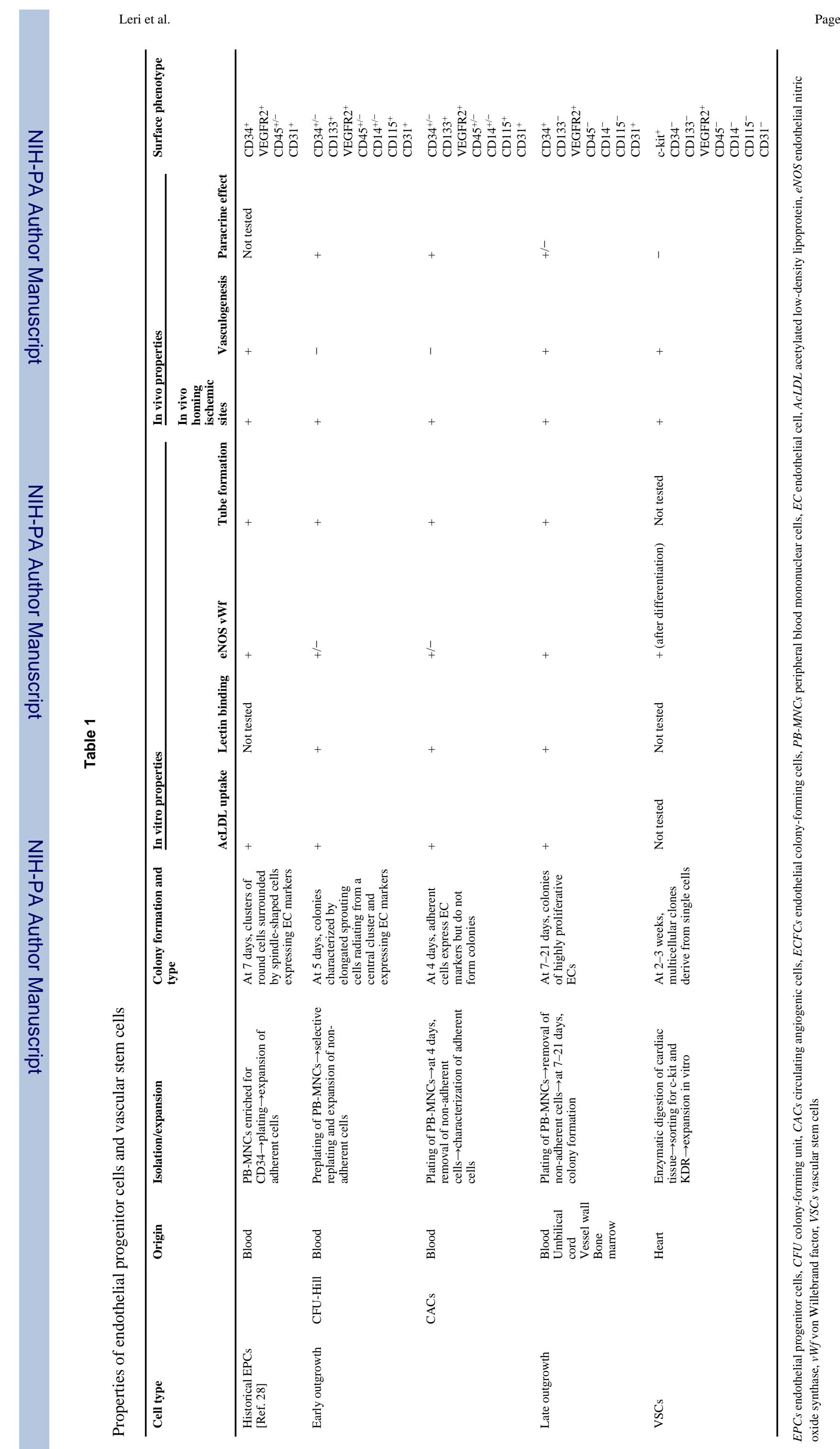

